\title{
Neuronal migration defects in the Loa dynein mutant mouse
}

Kassandra M Ori-McKenney ${ }^{1,2}$ and Richard B Vallee ${ }^{1 *}$

\begin{abstract}
Background: Cytoplasmic dynein and its regulatory proteins have been implicated in neuronal and non-neuronal cell migration. A genetic model for analyzing the role of cytoplasmic dynein specifically in these processes has, however, been lacking. The Loa (Legs at odd angles) mouse with a mutation in the dynein heavy chain has been the focus of an increasing number of studies for its role in neuron degeneration. Despite the location of this mutation in the tail domain of the dynein heavy chain, we previously found a striking effect on coordination between the two dynein motor domains, resulting in a defect in dynein run length in vitro and in vivo.

Results: We have now tested for effects of the Loa mutation on neuronal migration in the developing neocortex. Loa homozygotes showed clear defects in neocortical lamination and neuronal migration resulting from a reduction in the rate of radial migration of bipolar neurons.

Conclusions: These results present a new genetic model for understanding the dynein pathway and its functions during neuronal migration. They also provide the first evidence for a link between dynein processivity and somal movement, which is essential for proper development of the brain.
\end{abstract}

\section{Background}

Cytoplasmic dynein is a minus-end directed microtubule motor protein involved in a wide variety of functions. In order to perform such diverse activities in the cell, dynein makes use of numerous regulatory partners, including dynactin, LIS1, NudE and NudEL [1-3]. LIS1 and $\mathrm{NudE} / \mathrm{L}$, in particular, have received considerable attention for their role in brain development [4-7]. Sporadic mutations in LIS1 cause type I, or classical, lissencephaly, a severe brain developmental disease characterized by a smooth cortical surface [8]. Patients with lissencephaly exhibit lamination defects of the cerebral cortex, consistent with a defect in neuronal migration. Developmental analysis of LIS1 mutant mouse lines has shown that a reduction of LIS1 protein leads to neocortical organization defects in a dose-dependent manner [5,9-11]. Live analysis of embryonic rat brain subjected to LIS1 RNA interference (RNAi) has directly demonstrated defects in neural progenitor cell division, radial migration, and axon elongation [7,12]. The genes

\footnotetext{
* Correspondence: rv2025@columbia.edu

'Department of Pathology and Cell Biology, Columbia University, New York, NY 10032, USA

Full list of author information is available at the end of the article
}

encoding NudE and NudEL, Nde1 and Ndel1, are closely related and interact genetically with LIS1 and cytoplasmic dynein [13]. Nde1 and Ndel1 mutant mice exhibit either microcephalic or lissencephalic brain phenotypes, consistent with a functional relationship to LIS1 [6,14-16].

Several studies have focused on the role of genes in the dynein pathway in mammalian brain development. However, there are no genetic models with which to study the involvement of dynein directly. Mice homozygous null for the cytoplasmic dynein heavy chain gene exhibit early embryonic lethality, whereas heterozygotes show no obvious abnormalities [17]. However, several dynein mutant mouse strains have since been identified in screens for genes involved in neurodegeneration $[18,19]$. Of these dynein mutants, the Loa mutation has received particular attention $[20,21]$. The Loa heterozygous mice are viable and develop early onset neurodegenerative disease, but the homozygous animals die perinatally due to an inability to feed [18]. Interestingly, both the Loa/+ and the Loa/Loa mice exhibited defects in retrograde axonal transport $[18,22]$. The Loa mutation resides in the amino-terminal tail region of the dynein heavy chain. Nonetheless, enzymatic, biochemical, and single molecule 
analysis revealed a decreased microtubule affinity for the Loa mutant dynein due to a disruption in the coordination of its two motor domains [23]. This defect was manifested as a decrease in processivity for purified mutant dynein in in vitro single molecule assays. Particle tracking of lysosome/late endosome transport in cultured wildtype and Loa hippocampal neurons revealed a marked reduction in vesicular run lengths that could be accounted for quantitatively by the reduced processivity of the mutant dynein [23].

The Loa mouse represents an important model for the study of neurodegeneration. It should also, in principle, be useful in evaluating the role of dynein in other functions, such as neuronal migration. In view of its particular effects on dynein mechanochemical behavior, Loa also affords an opportunity to test whether dynein processivity contributes to this process. The Loa/Loa mice have been reported to display abnormal facial motor neuron organization, suggesting potential cellular migration defects [18]. We report direct evidence that the Loa mutation disrupts this process, causing a delay in neocortical development, a result that confirms a more general value for this mutant mouse strain and has implications for the role of motor processivity in neuronal migration.

\section{Results}

\section{Lamination defects in homozygous Loa mutant mice}

To test whether the Loa mutation affects brain development, we first examined the lamination pattern of the cerebral cortex in postnatal day zero (P0) mouse pups. Wild-type and Loa/Loa brains had a similar cortical thickness: $1,198 \pm 150 \mu \mathrm{m}$ for wild type versus $1,220 \pm$ $160 \mu \mathrm{m}$ for Loa/Loa $(P=0.8705 ; \mathrm{n}=3$ brains per genotype). Six distinct layers could be identified by DAPI staining in both wild-type and Loa/+ brains; however, the boundaries were blurred in the Loa/Loa brains, especially between neuronal layers III and IV (Figure 1A). To identify individual layers, we measured the density of Ctip2 and Foxp2 staining, which serve as markers for layers III and VI, respectively. In the Loa/Loa brains, Ctip2-positive cells were spread over an area roughly twice as broad as the compact layer observed in the wild-type brain (Figure $1 \mathrm{~B} ; P<0.005 ; \mathrm{n}=3$ brains per genotype). In contrast, there were fewer Foxp2-positive cells in layer VI of the Loa/Loa brain compared with wild type (Figure $1 \mathrm{C} ; P<0.005 ; \mathrm{n}=3$ brains per genotype), a further indication of cortical disorganization.

We also examined the hippocampus of the Loa/Loa mutant brain and noticed that, although overall structure was normal, the dentate gyrus was smaller than in the wild-type brain (Figure 2A). We therefore analyzed the subset of granule neurons (labeled by Prox-1) that are born in the subventricular zone of the neocortex and migrate to form the dentate gyrus [24]. In the Loa/ Loa hippocampus, granule cell redistribution to the dentate gyrus was delayed at all time-points examined, and by $\mathrm{PO}$ the dentate gyrus was smaller and more compact than in the wild-type hippocampus (Figure 2B). Together our data revealed lamination defects in both the neocortical and hippocampal regions of the Loa/Loa mouse that were similar to, though less severe than, those reported in the LIS1 compound heterozygous mutant mice $[9,10]$.

\section{Loa/Loa brains exhibit defects in neuronal migration}

To explore the origin of the lamination abnormalities, we first performed a BrdU birthdating study by injection of pregnant Loa/+ mice with the thymidine analog 5bromo-2'-deoxyuridine (BrdU) at either embryonic day (E) 16 or 18 . BrdU is incorporated into the DNA of Sphase progenitor cells and serves as a stable marker for cells born around the time of injection. Brains from pups exposed to the label at E16 or E18 were analyzed for the distribution of BrdU-positive cells at P0. In wildtype brains, E16 BrdU-labeled cells formed a compact layer near the pial surface by P0 (Figure 3A). In the Loa/Loa brains, the majority of BrdU-positive cells migrated to the same cortical region of the brain, but formed a broader layer and showed many trailing neurons (Figure 3A; $P<0.005$ for cell density within the first two cortical layers; $n=3$ brains per genotype). A similar effect was observed with neurons labeled with BrdU at E18: the neurons showed a reduced migration distance, as well as a more scattered distribution in the Loa/Loa mutants relative to wild-type controls (Figure 3B; $P<0.001$ for cell density within the first two cortical layers; $\mathrm{n}=3$ brains per genotype).

We also introduced GFP cDNA into neural progenitor cells in the mouse neocortex by in utero electroporation at E15 [25]. GFP-positive cells in the ventricular zone/subventricular zone, intermediate zone (IZ), and cortical plate (CP) were examined 3, 4, or 5 days later (Figure $4 ; \mathrm{n}=3$ brains per genotype, per time-point). In the wild-type brains, $27 \%$ of the transfected neurons had reached the $\mathrm{CP}$ by day 3 (E18), and $57.5 \%$ by day 4 (Figure $4 \mathrm{~A}, \mathrm{C}$ ), a time-course consistent with previous observations [26,27]. In Loa/ Loa brains, however, the majority of transfected cells remained within the ventricular zone and subventricular zone at both day 3 and day 4 , with only a subset having reached the IZ (Figure $4 \mathrm{~B}, \mathrm{C} ; 45 \%$ by day $4 ; P<$ 0.01 ). However, by day 5 , the distribution of GFP-positive cells in Loa/Loa brains was almost identical to that at day 3 in the wild-type brains (Figure 4B,C; 22\% in the CP of Loa/Loa brains). Thus, the Loa mutation delays the radial redistribution to the $\mathrm{CP}$ by approximately 2 days in the mouse neocortex. 


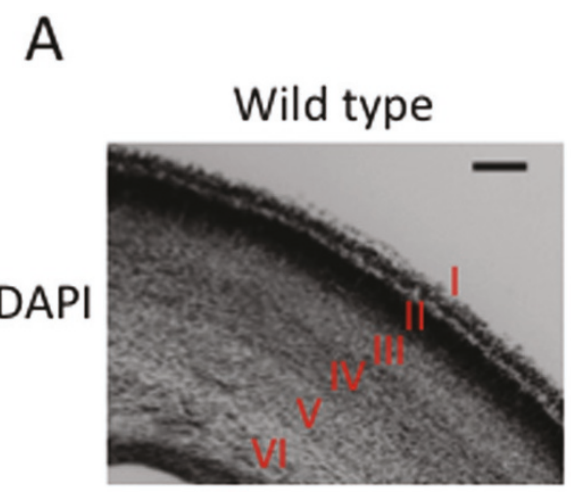

Ventricle

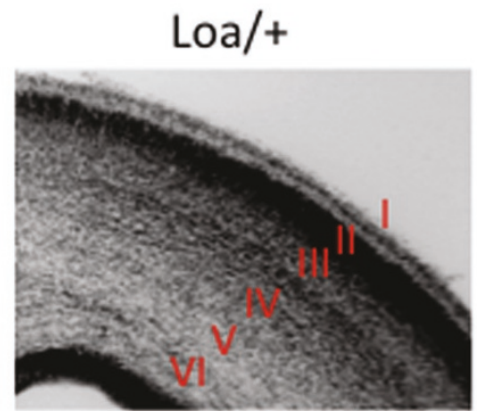

Ventricle

\section{Loa/Loa}

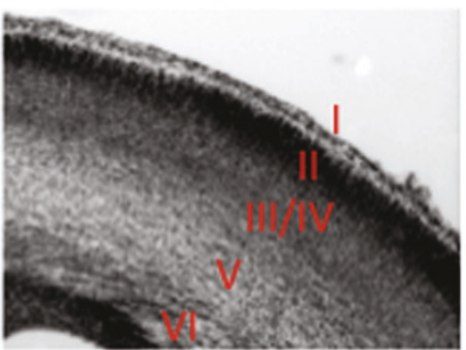

Ventricle

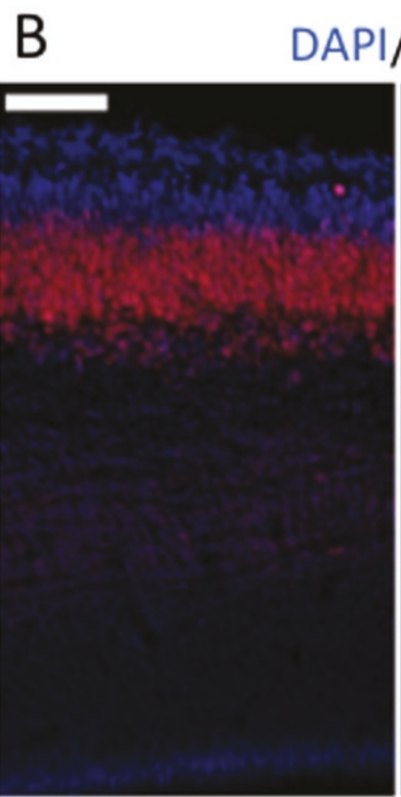

Wild type

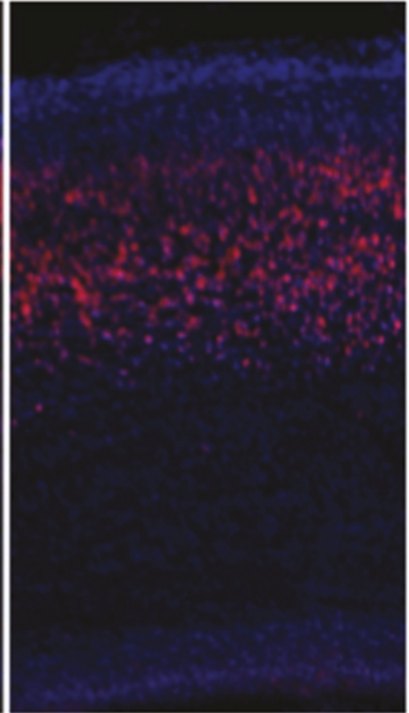

Loa/Loa

C

DAPI/Foxp2

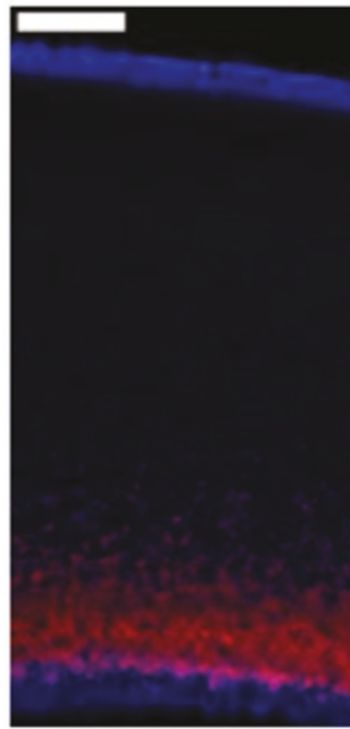

Wild type

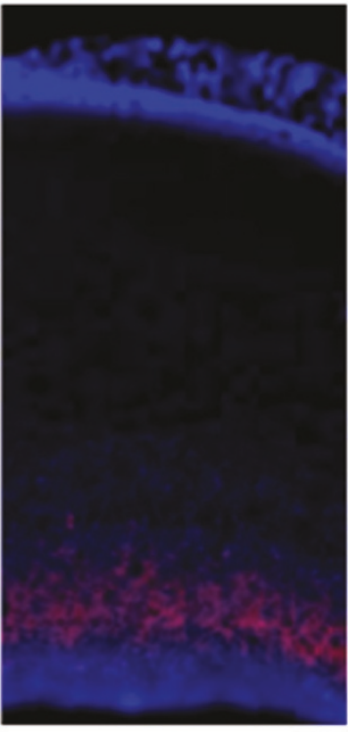

Loa/Loa
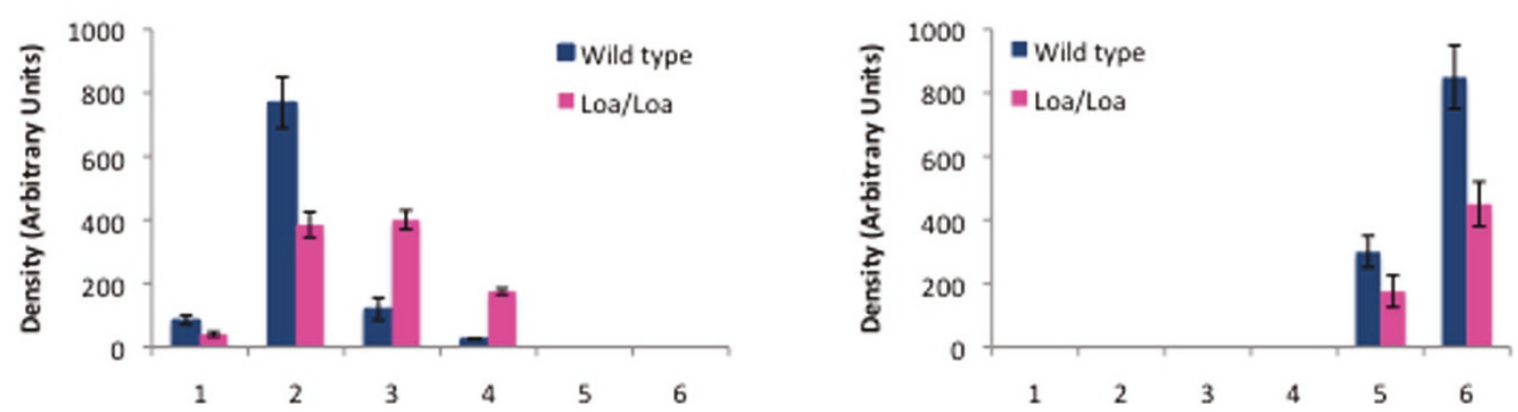

Figure 1 Cortical defects are apparent in the brains of Loa/Loa animals, but not in the brains of Loa/+ or wild-type mice. (A) Brain sections stained with DAPI reveal six distinct layers, labeled I to VI, in wild-type and Loa/+ brains, but blurred layer boundaries in the Loa/Loa brains. Scale bar $=200 \mu \mathrm{m}$. (B) Wild-type and Loa/Loa brain slices stained with Ctip2, which labels neurons in layers II/III. Brain sections were divided into six equal regions and the corresponding graph shows the mean Ctip2 density within each of these regions for each genotype. Error bars represent the standard deviation. Scale bar $=200 \mu \mathrm{m}$. (C) Wild-type and Loa/Loa brain slices stained with Foxp2, which labels neurons in layer VI. Brain sections were divided into six equal regions and the corresponding graph shows the mean Foxp2 density within each of these regions for each genotype. Error bars represent the standard deviation. Scale bar $=200 \mu \mathrm{m}$. 


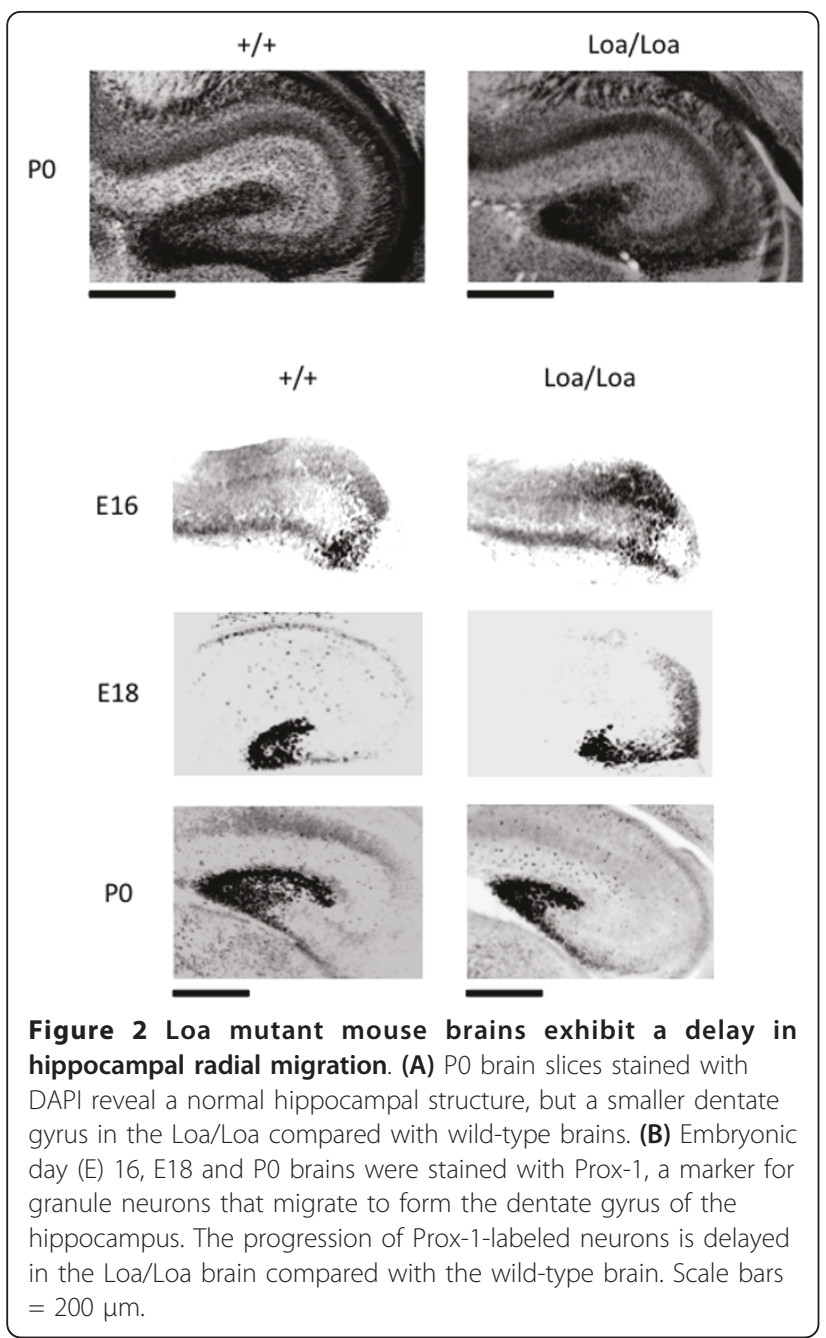

Live cell imaging reveals a decreased rate of somal translocation

To obtain further insight into the basis for the delay in neuronal redistribution, we performed live cell imaging of E16 wild-type and Loa/Loa brain slices labeled with Oregon Green BAPTA AM. Labeled cells within the IZ exhibited the normal bipolar morphology of radially migrating neurons. The rates of neuronal movement towards the pial surface varied with time and from cell to cell as previously reported [12,28,29] (Figure 5). The tip of the leading process progressed at a similar average rate for both wild-type and Loa/Loa neurons (0.16 \pm $0.10 \mu \mathrm{m} / \mathrm{minute}$ and $0.17 \pm 0.11 \mu \mathrm{m} / \mathrm{minute}$, respectively; $P=0.817$ ). However, the rate of somal translocation was significantly different between genotypes, with an average rate of $0.38 \pm .09 \mu \mathrm{m} /$ minute for wild-type neurons, but only $0.23 \pm 0.6 \mu \mathrm{m} /$ minute for Loa/Loa neurons (Figure 5A-C; $P<0.0001 ; \mathrm{n}=12$ cells from at least three brains per genotype followed for at least 110 minutes).

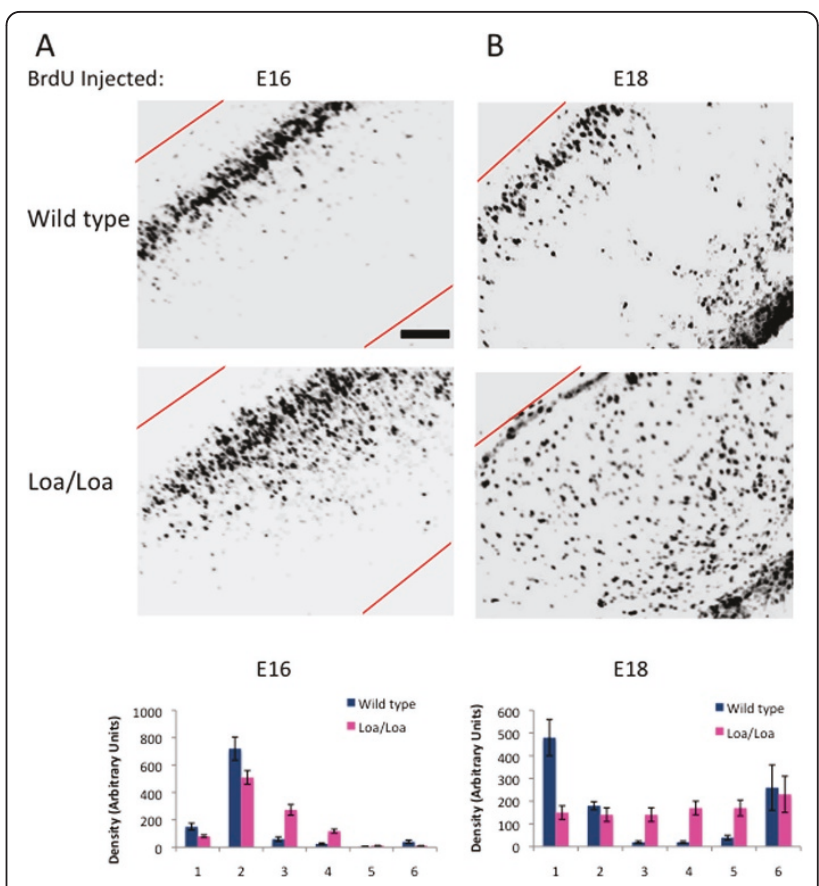

Figure $3 \mathrm{BrdU}$ birthdating study reveals defects in neuronal migration in the Loa/Loa mutants. $(A, B)$ Pregnant mice were injected with BrdU at either E16 (A) or E18 (B), and wild-type and Loa/Loa littermates were sacrificed at PO. (A) Migration of E16 BrdUlabeled neurons in wild-type and Loa/Loa brain slices reveals a delay in migration for the Loa/Loa neurons, which is quantified in the graph below (mean density of BrdU-positive cells \pm standard deviation). (B) Migration of E18 BrdU-labeled neurons in wild-type and Loa/Loa brain slices reveals a delay in migration for the Loa/Loa neurons, which is quantified in the graph below (mean density of BrdU-positive cells \pm standard deviation). Scale bar $=200 \mu \mathrm{m}$.

Many cell bodies of the migrating wild-type and Loa/ Loa neurons were distorted into an elongated shape during migration. However, the wild-type cell bodies remained in this stretched conformation for $20.0 \pm 11.5$ minutes before returning to their normal rounded morphology after advancing, whereas Loa/Loa cell bodies remained in the stretched state for $38.0 \pm 13.0$ minutes (Figure 5A,B; $P<0.05 ; \mathrm{n}=12$ ). These results are indicative of a prolonged somal translocation state due to the reduced transport by the Loa mutant motors.

\section{Changes in mitotic progression are not detected in Loa progenitors}

Cytoplasmic dynein is involved in numerous aspects of mitosis, including mitotic spindle organization and orientation, interactions of kinetochores with microtubules, and mitotic checkpoint regulation [30-34]. To test for accumulation of dynein mutant cells in mitosis, we stained wild-type and Loa/Loa E16 brain slices with an antibody to phospho-histone 3 (PH3). Although we did find a slight increase in the number of $\mathrm{PH} 3$-positive 


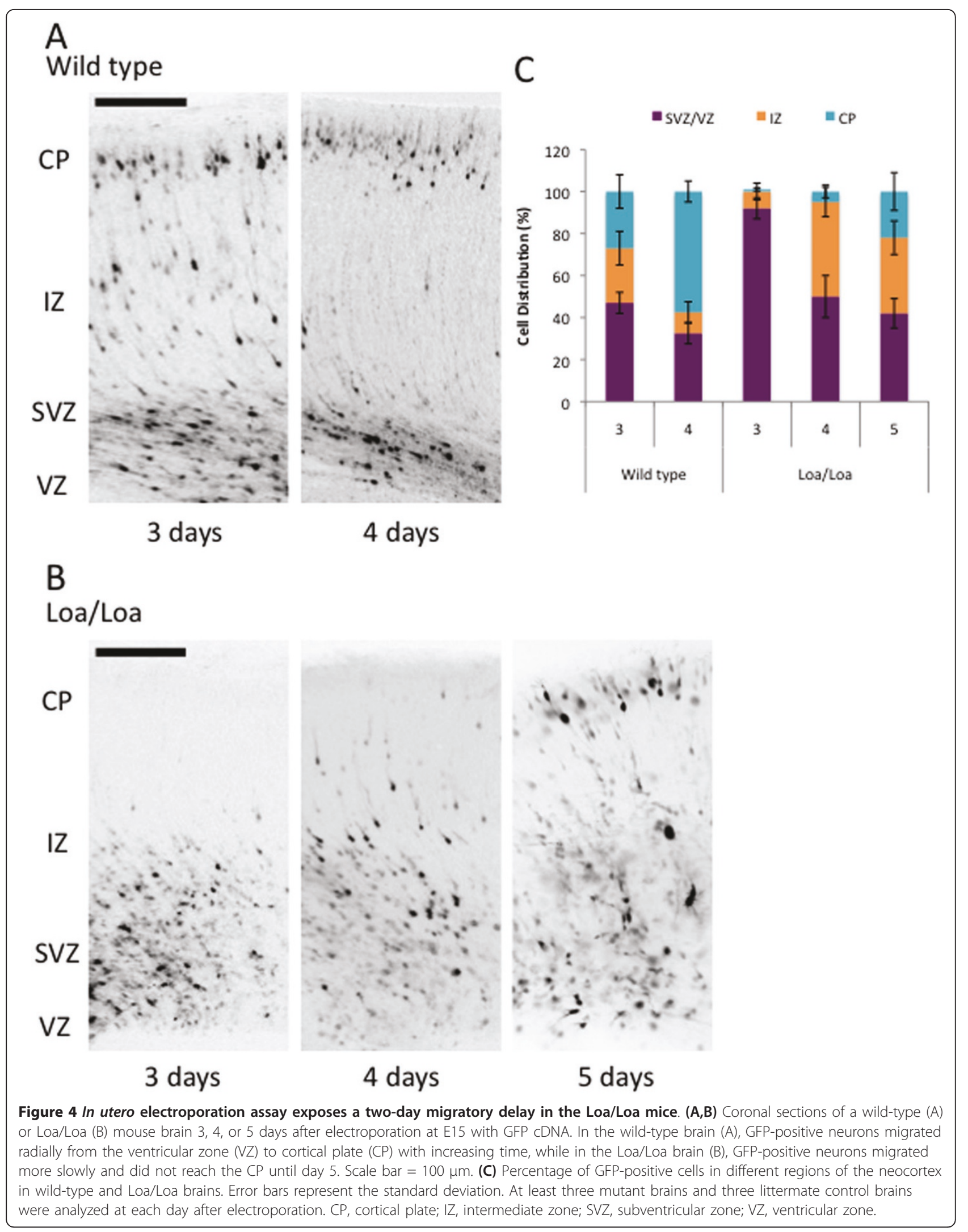




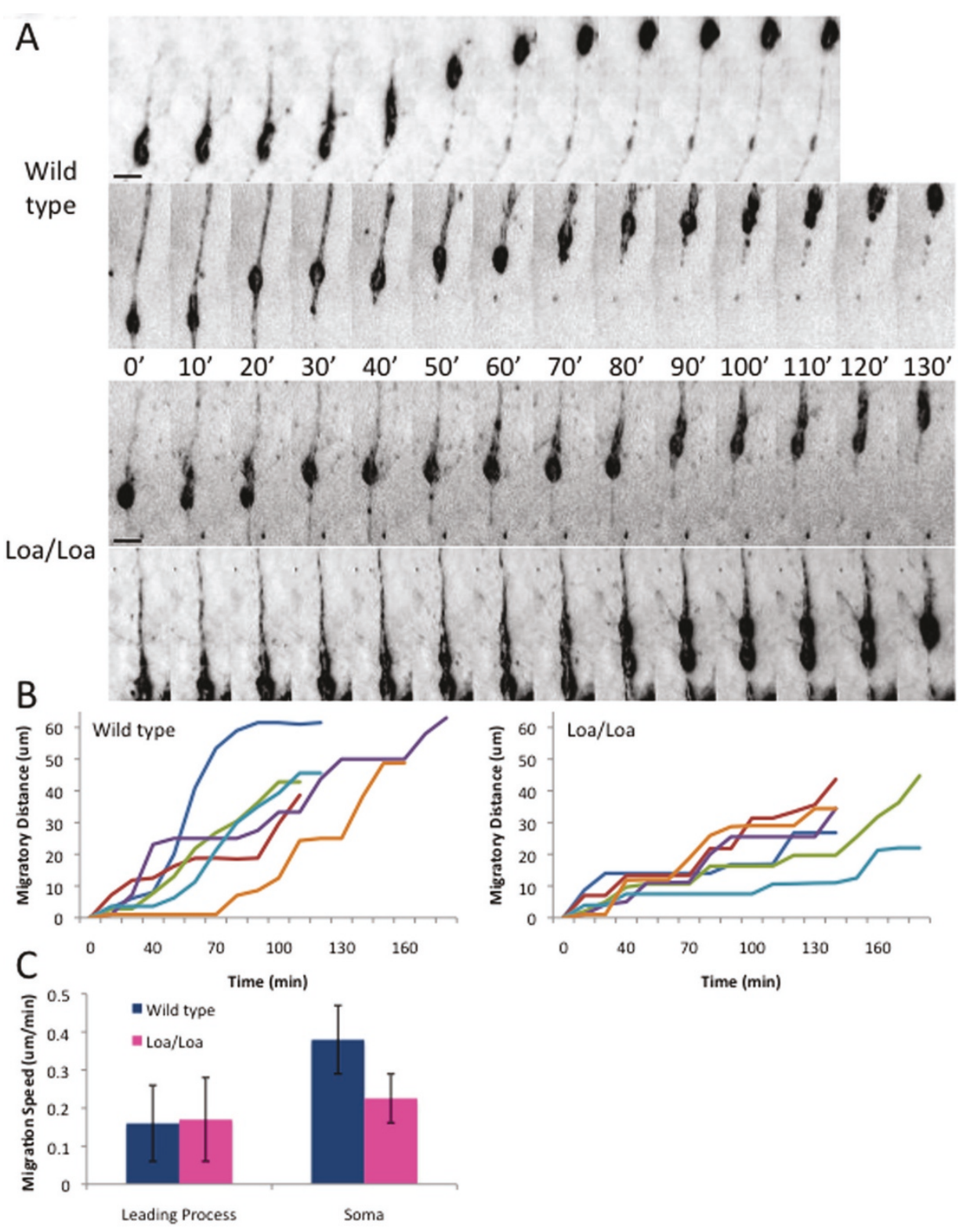

Figure 5 Live cell imaging of radial migration in the intermediate zone. Mouse brains were sectioned and incubated with Oregon Green BAPTA-1 488 AM, and the labeled bipolar cells were imaged within the IZ. (A) Kymographs of somal translocation within the neurons of the wild-type and Loa/Loa mouse brains. Time is shown in minutes. Scale bar $=10 \mu \mathrm{m}$. (B) Tracings of cell body position for six representative wildtype neurons and six representative Loa/Loa neurons show a slower progression of somal movement in the Loa/Loa neurons. (C) Graph depicting the average rates of leading process outgrowth and somal translocation ( \pm standard deviation) for wild-type and Loa/Loa neurons $(P<$ 0.0001 for somal translocation; $n=12$ cells from at least three brains per genotype followed for at least 110 minutes).

cells in the Loa/Loa brain slices compared with wild type, this difference was not statistically significant (Figure $6 \mathrm{~A} ; P=0.054 ; \mathrm{n}=5$ brain slices per genotype). Similarly, counts of PH3-positive cells located in the ventricular or abventricular ( $>100 \mu \mathrm{m}$ from the ventricle) regions were not significantly different between wild-type and Loa/Loa brains (Figure 6A; $P=0.068 ; \mathrm{n}=$ 5 brain slices per genotype). As an additional test for impaired cell cycle progression, we performed a 2-hour
BrdU pulse in E16 mice and found a similar number of BrdU-positive cells in wild-type versus mutant brain (Figure 6B). We also observed a comparable fraction of Pax6-positive cells between wild-type and Loa/Loa brains at both E16 and E18 (data not shown). Wild-type and Loa/Loa brains are of comparable size and have a similar cortical thickness (Figure 1); thus, together, these results argue against the gross mitotic defects that have been reported for a NudE null mouse [6]. 


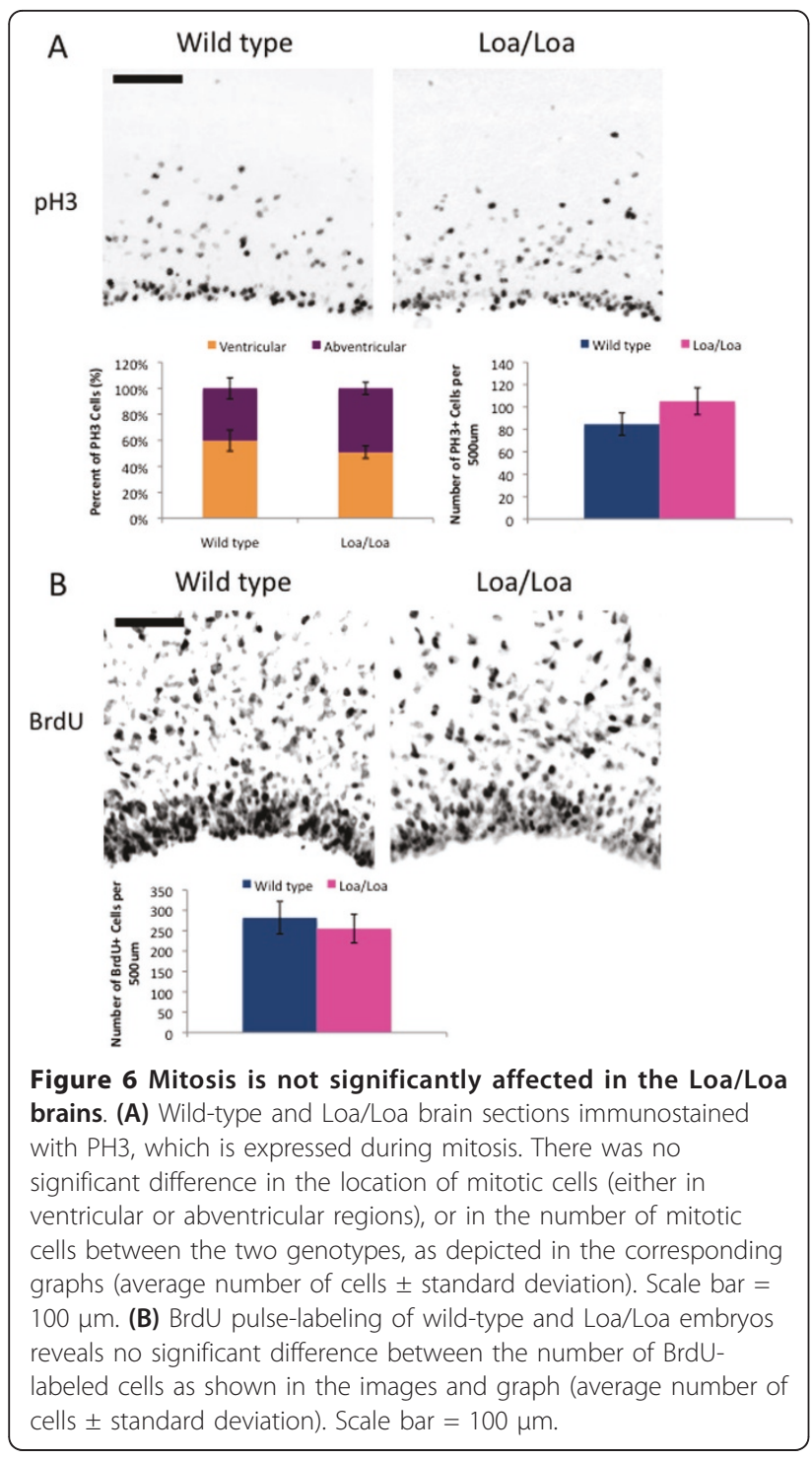

\section{Axon extension is reduced in Loa/Loa neurons}

Dynein and its regulatory factors, dynactin and LIS1, have been implicated in axon elongation in rat brain slices subjected to LIS1 RNAi and in cultured neurons $[7,35,36]$. Oregon Green BAPTA staining could detect clear trailing axons in a majority of radially migrating neurons in wild-type mice (Figure 7A,C; 72.3\%; $\mathrm{n}=32$ cells from three brain slices); however, axons were detectable in fewer neurons in Loa/Loa slices (Figure 7B,C; 50.6\%; $\mathrm{n}=30$ cells from three brain slices; $P<$ 0.0001 ). Of the visible axons, $62.5 \%$ of the wild-type axons could be followed for longer than $40 \mu \mathrm{m}$ compared with only $40.0 \%$ of the Loa/Loa axons (Figure 7D). We also observed a decrease in axon extension for Loa/Loa neurons in vitro. We cultured neurons on laminin for 2 or 3 days in vitro (DIV), then examined axonal length. At DIV2, the average axon length of wild-type

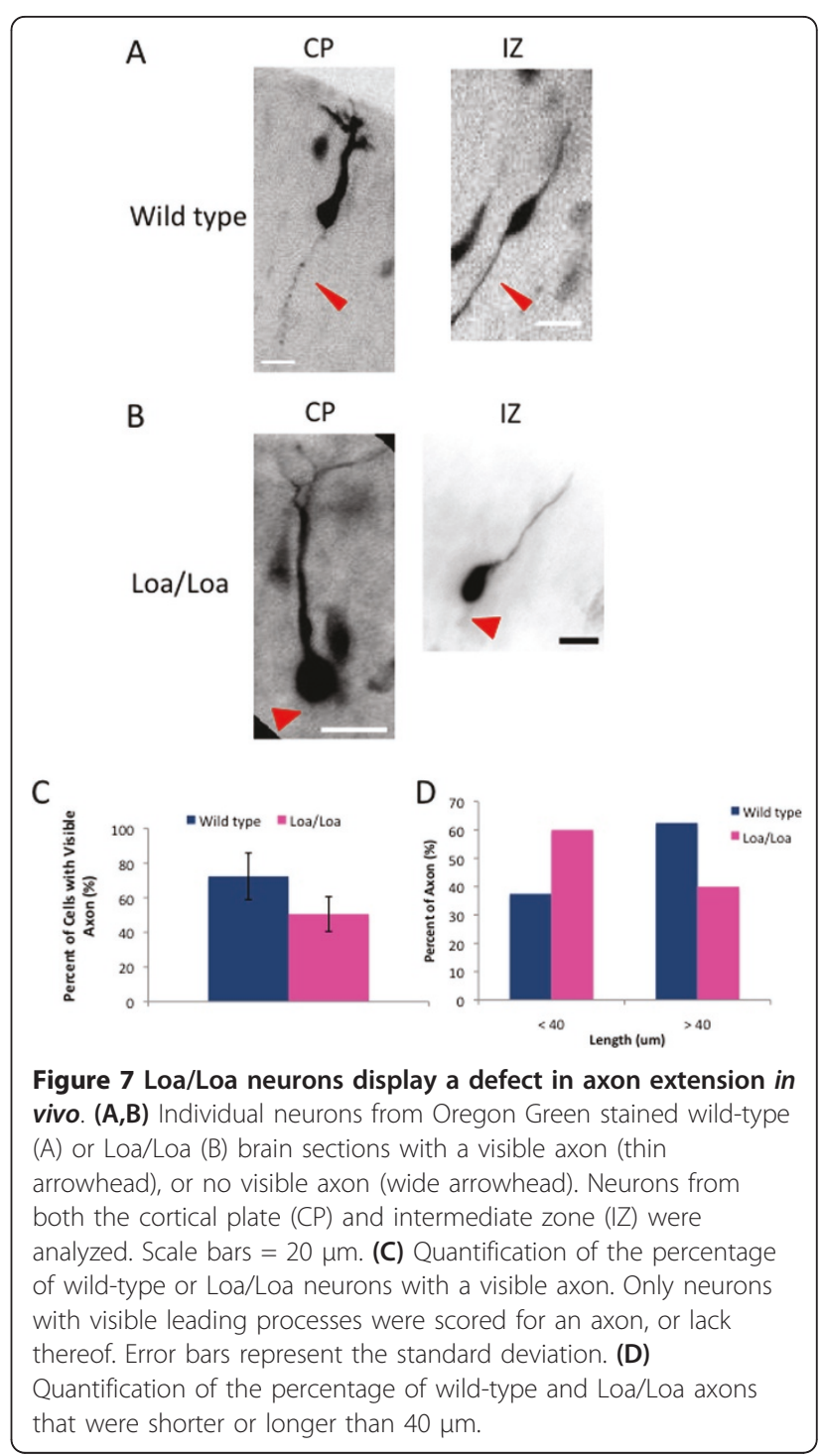

neurons was $111 \pm 23 \mu \mathrm{m}$ compared with $54 \pm 19 \mu \mathrm{m}$ for the Loa/Loa neurons ( $\mathrm{n}=57$ and 53 neurons, respectively; $P<0.0001$ ), and by DIV3, the average axon length of wild-type neurons was $125 \pm 27 \mu \mathrm{m}$ compared with $89 \pm 28 \mu \mathrm{m}$ for the Loa/Loa neurons $(\mathrm{n}=60$ and 55 neurons, respectively; $P<0.0001$ ) (Figure 8A,B). Together with our earlier results [23], these results reveal that dynein processivity is necessary for axon elongation.

\section{Loa/Loa mutant dynein can still bind its regulatory proteins}

We previously reported that the Loa mutation specifically affects the processivity of dynein due to apparent miscoordination of the motor domains. We observed no change in the association of the mutant dynein with isolated neuronal membranes, further indicating that the 


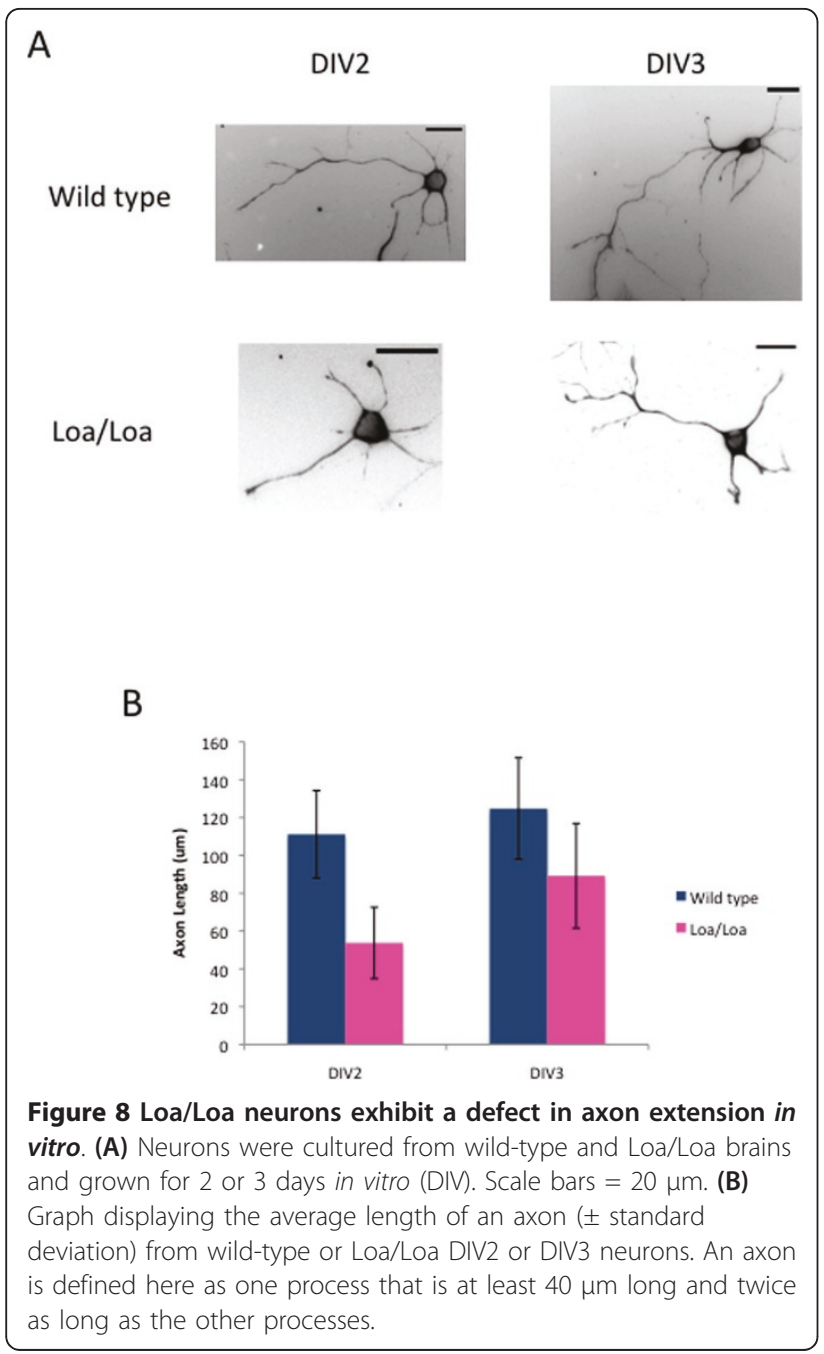

physiological effects of Loa could be accounted for by altered mechanochemical activity alone [23]. However, because the cytoplasmic dynein regulators NudE, LIS1, and dynactin are also associated with brain development, we tested the mutant dynein further for its ability to interact with these factors. We performed pull-downs with purified proteins rather than immunoprecipitations with a dynein intermediate chain antibody, which might interfere with these interactions. Pull-downs from brain cytosol with recombinant glutathione S-transferase (GST NudE revealed no difference in the associated dynein or LIS1 between wild-type and Loa/Loa mutants (Figure 9A,C; $66.2 \pm 8.8 \%$ and $57.7 \pm 9.1 \%$ of heavy chain in the NudE pellet, respectively; $P=0.310$ ). We similarly tested the GST-tagged CC1 fragment from the dynactin subunit $\mathrm{p} 150^{\text {Glued }}$, which interacts with the dynein intermediate chain $[37,38]$. Comparable levels of wild-type and Loa/Loa dynein were again found in the CC1 pull-downs (Figure 9B,C; $45.3 \pm 2.2 \%$ and $40.7 \pm$
$10.7 \%$ of heavy chain in the pellet, respectively; $P=$ 0.506). Therefore, the developmental defects we observe in the Loa/Loa mice likely reflect intrinsic abnormalities in the mutant dynein.

\section{Discussion}

We find that Loa mutant mice exhibit defects in cortical and hippocampal development. Using live cell imaging techniques, we found direct evidence for a migration delay of bipolar neurons. Our results further indicate that this effect is not associated with defects in dynein interactions with LIS, NudE, or dynactin, and is therefore likely to result directly from the inherent mechanochemical defects caused by the Loa mutation [23].

The abnormal cortical lamination we observe in the Loa/Loa mouse brain is similar to that seen in LIS1 compound heterozygous mutant mice [5,9]. LIS1 mice exhibit severe disorganization of pyramidal cells in the CA1, CA2, and CA3 regions, as well as a reduced density of granule cells in the dentate gyrus $[9,39]$. We observe a clear delay in the migration of granule neurons in the Loa/Loa mouse to form the dentate gyrus. Although the formation of the dentate gyrus has not been examined in the LIS1 mice, a delay in granule cell migration could provide a potential explanation for the diminished size of the dentate gyrus in these mice.

We detected a decrease in axon extension in Loa/Loa neurons both in vivo and in vitro, as well as a decrease in axon length. Dynein as well as LIS1 are necessary for the reorganization and extension of the growth cone during axonogenesis $[7,35,36]$. These proteins are required to help microtubules extending into the peripheral zone of the growth cone resist retrograde actin flow [36]. A Loa mutant dynein detaches from microtubules about twice as frequently as the wild-type motor protein [23]. Therefore, microtubule penetration into the peripheral zone could be compromised, providing an explanation for altered axon elongation.

Altered expression of LIS, cytoplasmic dynein, and NudE have each been found to affect mitotic index in the developing brain $[6,7,40]$. These effects reflect direct roles for these proteins in mitosis [31,41,42]. Furthermore, LIS1 and cytoplasmic dynein RNAi interfere with apical migration of radial glial nuclei to the ventricular surface, which has been found to be essential for mitotic entry $[7,43]$. The similarity in mitotic index between Loa/Loa and wild-type mouse brains suggests that any effect on mitotic entry or progression must be relatively minor, though further live analysis of mitosis might still reveal altered mitotic behavior.

The current study indicates that the Loa mutation affects neuronal migration in a similar manner as reduced LIS1 expression $[5,7,9]$. However, the Loa mutation affects dynein processivity [23], whereas LIS1 contributes to 


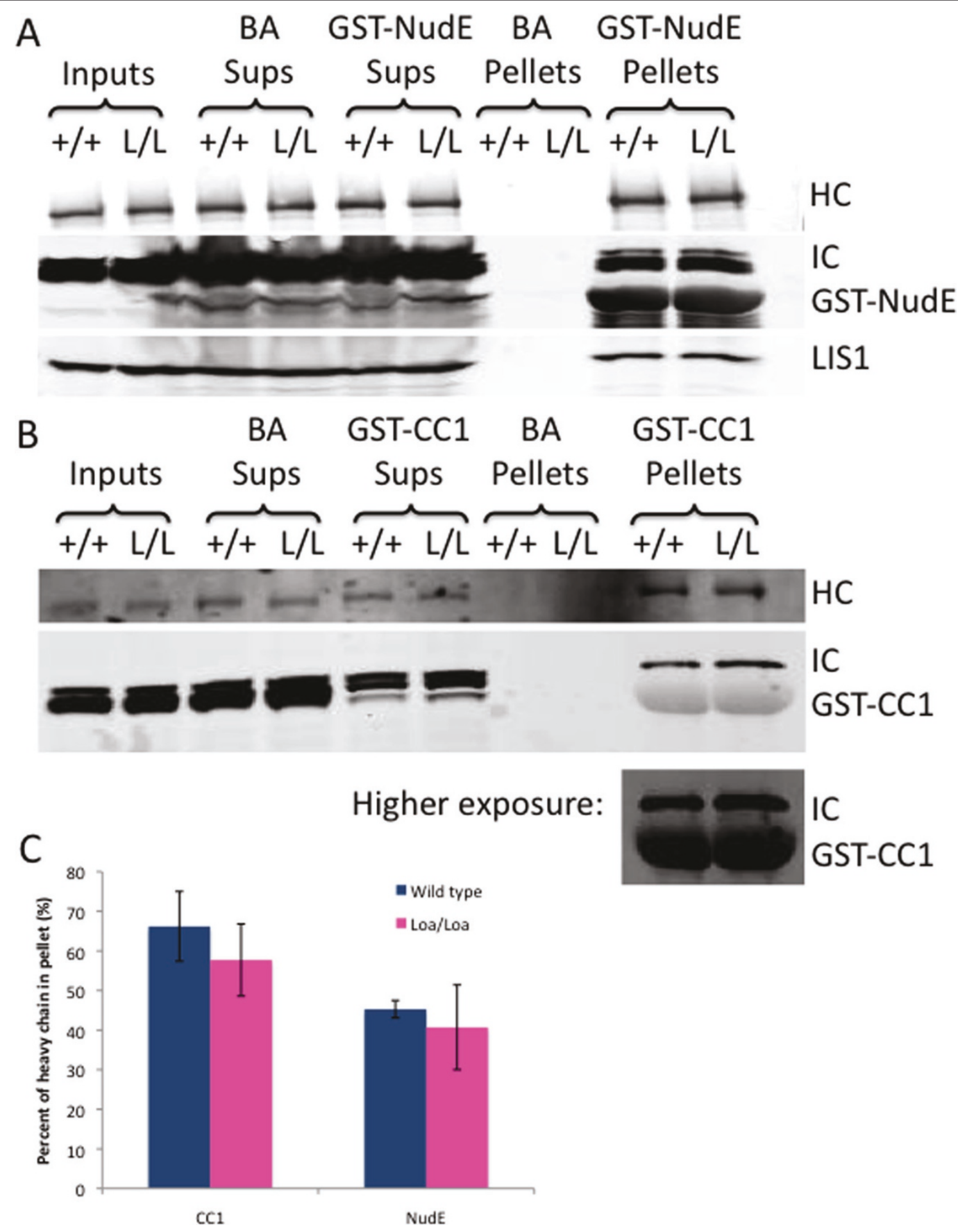

Figure 9 Loa/Loa dynein can still bind its regulatory partners. (A) GST-NudE pull-down assay from wild-type and Loa/Loa brain lysate. Input is $30 \%$ of total. Immunoblot reveals that protein is not pulled down by beads alone (BA), but similar amounts of both wild-type (+/+) and Loa/ Loa (L/L) dynein (as shown by immunoblotting for dynein heavy chain and dynein intermediate chain) along with LIS1, are pulled down by GSTNudE. HC, heavy chain; IC, intermediate chain. (B) GST-CC1 pull-down assay from wild-type and Loa/Loa brain lysate. Input is $30 \%$ of total. Immunoblot reveals that dynein is not pulled down by beads alone (BA), but similar amounts of both wild-type (+/+) and Loa/Loa (L/L) dynein (as shown by immunoblotting for dynein heavy chain and dynein intermediate chain) are pulled down by GST-CC1. A higher exposure blot reveals the GST-CC1 band below the IC band. (C) Graph depicting the average percentage of wild-type or Loa/Loa dynein heavy chain ( \pm standard deviation) that is pulled into the pellet by either GST-NudE or GST-CC1 ( $n=3$ experiments per genotype). 
dynein force production [44]. Our results indicate, therefore, that different defects in dynein function can lead to a common developmental outcome. The mechanical basis for this result is uncertain, but is likely a consequence of the coordinate behavior of multiple dynein molecules during high load functions. In in vitro studies, LIS1 was found to convert cytoplasmic dynein to a persistent force-producing state, though the level of force generation by individual dynein molecules was unaffected. However, force generation by multiple motors is summated, and this effect was further enhanced by LIS1 as revealed in in vitro laser trap bead assays and in computational simulations [44]. Thus, LIS1 appears to be ideally suited for a role in high load functions such as nuclear transport $[12,44]$. The Loa mutation, in contrast, had a clear effect on motor processivity [23]. How the Loa mutation might affect transport of high load structures is uncertain, but could also involve coordination of multiple dynein molecules. The Loa mutation results not only in decreased single molecule processivity in vitro, but also in decreased run-lengths for lysosomes/late endosomes in vivo, which are thought to be driven by an average of approximately five to seven dyneins $[23,45,46]$. Computational modeling indicates that, although cargo run length increases with motor number, the Loa processivity defect extends to the multimotor condition [23]. Thus, defects in neuronal migration could conceivably be explained by a reduction in run length during nuclear transport. We reason, however, that Loa should also affect aggregate force production by multiple motors, which is a reflection of the number of individual motors simultaneously 'engaged' with microtubules at any given time. This value should be reduced for Loa as a simple consequence of its increased microtubule detachment rate. Thus, the defect in neuronal migration we observe in the Loa/Loa mouse could result from shorter nuclear run lengths, decreased force, or both. The prolonged state of somal distortion we observe during neuronal migration in the Loa/Loa neurons could be indicative, in particular, of a reduction in nuclear translocation forces, but further work will be needed to directly determine the effects of the Loa mutation at the multiple motor level.

The defects we observe in the mutant neurons may explain the perilethality of the Loa/Loa mice. The Loa homozygotes die within 24 hours of birth due to an inability to move their mouths, and therefore feed. A 2day delay in the migration of facial motor neurons to their destination may be responsible for this facial paralysis. Correspondingly, a delay in axon extension could also contribute to facial paralysis due to a lack of muscle innervation.

\section{Conclusions}

Our results reveal a clear effect of the Loa mutation on neuronal migration, in addition to its previously reported effects on retrograde vesicular transport and on motor and sensory neuron viability. Our observations establish the utility of the Loa mouse as a hypomorphic dynein mutant model for the investigation of not only neurodegeneration but also general cytoplasmic dynein function.

\section{Materials and methods \\ Animals}

Mice were housed in standard cages on a 12:12 light: dark schedule at $25^{\circ} \mathrm{C}$. All experimental research was performed according to the guidelines of the Institutional Animal Care and Use Committee (IACUC). All experimental analyses were performed on mutant animals with littermate-matched controls.

\section{Immunohistochemistry}

Brains were fixed in $4 \%$ paraformaldehyde for 24 hours after extraction, then transferred to phosphate-buffered saline (PBS) until sectioning. Brains were sectioned on a Vibrotome (Leica VT 1200S) into 50- $\mu$ m thick slices. For staining with primary antibodies, slices were blocked at room temperature for 1 hour in PBS with $10 \%$ donkey serum and $1 \%$ Triton X-100. For antibodies requiring antigen retrieval (such as Foxp2), slices were boiled in $10 \mathrm{mM}$ sodium citrate buffer ( $\mathrm{pH} \mathrm{6)}$, then cooled back to room temperature before blocking. Primary antibodies were applied overnight at $4^{\circ} \mathrm{C}$ in PBS with $1 \%$ donkey serum and $0.1 \%$ Triton-X-100 at the following dilutions: anti-ctip2, 1:500 (rat; Abcam, Cambridge, MA, USA); anti-foxp2, 1:200 (rabbit; Abcam); PH3, 1:500 (rabbit; Millipore, Billerica, MA, USA); Prox1, 1:500 (rabbit; Abcam); Pax6, 1:200 (rabbit; Covance, Princeton, NJ, USA); and TujI, 1:500 (mouse; Covance). Slices were then washed in PBS and incubated with Cy2, Cy3, or Cy5 secondary antibodies (1:1,000; Jackson ImmunoResearch Laboratories, West Grove, PA, USA). Sections were mounted onto slides using VECTASHIELD HardSet Mounting Medium with DAPI (VectorLabs, Burlingame, CA, USA), then imaged on an Olympus IX81 inverted microscope. At least three brains per genotype were analyzed for each experiment.

\section{BrdU labeling and analysis}

For the BrdU birthdating assay in Figure 2, pregnant mice were injected intraperitoneally with BrdU at 100 $\mu \mathrm{g} / \mathrm{g}$ of body weight at either E16 or E18. The BrdUlabeled females were left to give birth and their offspring were sacrificed on P0. BrdU-positive cells in the cerebral cortex were detected by immunostaining with an antiBrdU antibody (1:200, rat; Abcam). This antibody required pre-treatment with $2 \mathrm{~N} \mathrm{HCl}$ for 15 minutes at $37^{\circ} \mathrm{C}$ prior to blocking. Staining was performed as described above. To analyze the BrdU-positive neurons 
in Loa/Loa mutants and their wild-type littermates, each brain section was divided into six equal regions, and the relative density and distribution of the BrdU-stained neurons in each region was plotted.

For the BrdU pulse-chase experiment in Figure 5B, pregnant mice were injected intraperitoneally with BrdU at $100 \mu \mathrm{g} / \mathrm{g}$ of body weight at E16. The mice were then sacrificed 2 hours after the injection to analyze the number of BrdU pulse-labeled cells at the ventricular surface in Loa/Loa and wild-type embryonic brains.

\section{In utero electroporation}

Plasmids were transfected using intraventricular injection followed by in utero electroporation as previously described [25]. Briefly, 1 to $2 \mu \mathrm{l}$ of GFP cDNA (concentration of 1 to $3 \mu \mathrm{g} / \mu \mathrm{l}$ ) were injected into the ventricle of embryonic brains at E15. A pair of copper alloy oval plates attached to the electroporation generator (Harvard Apparatus, Holliston, MA, USA) transmitted five electric pulses at $40 \mathrm{~V}$ for 50 milliseconds at 1 second intervals through the uterine wall. The embryos were then sacrificed 3, 4, or 5 days later and their brains were prepared as described above. The number of GFPlabeled neurons at the ventricular zone, subventricular/ intermediate zone, and cortical plate was plotted for Loa/Loa and wild-type littermates to assess the progression of neuronal migration from the ventricular surface.

\section{Organotypic slice cultures and live cell imaging}

These experiments were performed using a modified procedure of previously described methods $[28,47]$. Briefly, E16 brains were collected and sectioned coronally on a vibratome (Leica), then placed in a $50-\mathrm{mm}$ MatTek dish (MatTek Corporation, Ashland, MA, USA) containing imaging medium (F12/MEM medium with $10 \%$ fetal bovine serum and $1 \times$ penicillin/streptomycin (Invitrogen, Carlsbad, CA, USA) with $10 \mu \mathrm{g} / \mathrm{ml}$ of Oregon Green BAPTA-1 488 AM (Invitrogen). Slices were then incubated for 1 hour at $37^{\circ} \mathrm{C}$ with $5 \%$ $\mathrm{CO}_{2}$. After the incubation, the slices were washed in warmed PBS, then covered with a thin layer of Matrigel (BD Biosciences, San Diego, CA, USA) diluted $70 \times$ in imaging medium, then incubated again for $30 \mathrm{~min}-$ utes. The dish was then imaged in $1 \mathrm{ml}$ of additional imaging media with $10 \mathrm{mM}$ Hepes at $37^{\circ} \mathrm{C}$ with $5 \%$ $\mathrm{CO}_{2}$ on an Olympus IX81 inverted microscope. Images were captured every 10 minutes for 3 to 5 hours using an Hamamatsu ORCA-R2 CCD camera and Metamorph software (Molecular Devices, Sunnyvale, CA, USA. The speed of migration and length of axon were analyzed with Metamorph software. The position of the soma center was measured in each image and displacement of the soma was defined by the difference in location of the center between consecutive frames.
Therefore, the somal speed is described here as the displacement per unit time. The length of the axon was defined as the distance from the basal end of the soma to the tip of the process. Live cell imaging experiments and axon length measurements were performed on three brains per genotype.

\section{Biochemical assays}

Whole brain lysates from P0 wild-type and Loa/Loa mouse pups were used for the NudE and CC1 pulldowns. For each experiment, the lysate was first precleared with glutathione agarose 4B (USB Corporation, Cleveland, OH, USA) in order to prevent non-specific binding in the real assay. The beads were then spun down, and the pre-cleared lysate was used for the pulldowns. The pull-down solution contained the brain lysate, phosphate-glutamate buffer $(10 \mathrm{mM}$ sodium phosphate, $100 \mathrm{mM}$ sodium glutamate, $\mathrm{pH} 7.0$ with 1 $\mathrm{mM} \mathrm{MgSO}_{4}, 1 \mathrm{mM}$ EDTA, $1 \mathrm{mM}$ DTT, and 0.2\% NP40) up to $350 \mu \mathrm{l}$ and either beads alone, $1 \mu \mathrm{g} / \mu \mathrm{l} \mathrm{GST-}$ NudE [44] or $1 \mu \mathrm{g} / \mu \mathrm{l}$ GST-CC1 [37,38]. The solutions rotated at $4{ }^{\circ} \mathrm{C}$ for 2 hours, then the beads were spun down to separate the supernatants and pellets. The supernatants and pellets from each pull-down (beads alone, NudE, or CC1) were collected and analyzed by SDS-PAGE and western blot probing for dynein heavy chain (rabbit, 1:500) [48] and dynein intermediate chain (mouse, 1:1500; clone 74.1 provided by K Pfister, University of Virginia, Charlottesville, VA, USA). In the case of the NudE pull-down, we also probed for LIS1 (mouse, 1:1500; clone 338, Sigma, St. Louis, MO, USA).

\section{Abbreviations}

BrdU: 5-bromo-2'-deoxyuridine; CP: cortical plate; DIV: days in vitro; E: embryonic day; GFP: green fluorescent protein; GST: glutathione Stransferase; IZ: intermediate zone; Loa: Legs at odd angles; P: postnatal day; PBS: phosphate-buffered saline; PH3: phospho-histone 3; RNAi: RNA interference.

\section{Acknowledgements}

We thank Richard McKenney for providing the GST-NudE and GST-CC1 constructs, as well as for useful discussion. This work was supported by $\mathrm{NIH}$ grants GM47434 and HD40182 to RBV and GM008798-09 to KMOM, and the Columbia University Motor Neuron Center.

\section{Author details}

${ }^{1}$ Department of Pathology and Cell Biology, Columbia University, New York, NY 10032, USA. ²Department of Physiology, University of California, San Francisco, San Francisco, CA 94158, USA.

\section{Authors' contributions}

KMOM and RBV designed experiments, KMOM performed experiments and analyzed data, and KMOM and RBV wrote the manuscript. Both authors read and approved the final manuscript.

\section{Competing interests}

The authors declare that they have no competing interests. 


\section{References}

1. Schroer TA: Dynactin. Annu Rev Cell Dev Biol 2004, 20:759-779.

2. Vallee RB, Seale GE, Tsai JW: Emerging roles for myosin II and cytoplasmic dynein in migrating neurons and growth cones. Trends Cell Biol 2009, 19:347-355.

3. Kardon JR, Vale RD: Regulators of the cytoplasmic dynein motor. Nat Rev Mol Cell Biol 2009, 10:854-865.

4. Reiner O, Albrecht U, Gordon M, Chianese KA, Wong C, Gal-Gerber O, Sapir T, Siracusa LD, Buchberg AM, Caskey CT, Eichele G: Lissencephaly gene (LIS1) expression in the CNS suggests a role in neuronal migration. J Neurosci 1995, 15:3730-3738.

5. Cahana A, Escamez T, Nowakowski RS, Hayes NL, Giacobini M, von Holst A, Shmueli O, Sapir T, McConnell SK, Wurst W, Martinez S, Reiner O: Targeted mutagenesis of Lis1 disrupts cortical development and LIS1 homodimerization. Proc Natl Acad Sci USA 2001, 98:6429-6434.

6. Feng $Y$, Walsh CA: Mitotic spindle regulation by nde1 controls cerebral cortical size. Neuron 2004, 44:279-293.

7. Tsai JW, Chen Y, Kriegstein AR, Vallee RB: LIS1 RNA interference blocks neural stem cell division, morphogenesis, and motility at multiple stages. J Cell Biol 2005, 170:935-945.

8. Dobyns WB, Truwit CL: Lissencephaly and other malformations of cortical development: 1995 update. Neuropediatrics 1995, 26:132-147.

9. Hirotsune S, Fleck MW, Gambello MJ, Bix GJ, Chen A, Clark GD, Ledbetter DH, McBain CJ, Wynshaw-Boris A: Graded reduction of Pafah1b1 (Lis1) activity results in neuronal migration defects and early embryonic lethality. Nature Genetics 1998, 19:333-339.

10. Gambello MJ, Darling DL, Yingling J, Tanaka T, Gleeson JG, WynshawBoris A: Multiple dose-dependent effects of Lis1 on cerebral cortical development. J Neurosci 2003, 23:1719-1729.

11. McManus MF, Nasrallah IM, Pancoast MM, Wynshaw-Boris A, Golden JA: Lis1 is necessary for normal non-radial migration of inhibitory interneurons. Am J Pathol 2004, 165:775-784.

12. Tsai JW, Bremner KH, Vallee RB: Dual subcellular roles for LIS1 and dynein in radial neuronal migration in live brain tissue. Nat Neurosci 2007, 10:970-979.

13. Efimov VP, Morris NR: The LIS1-related NUDF protein of Aspergillus nidulans interacts with the coiled-coil domain of the NUDE/RO11 protein. J Cell Biol 2000, 150:681-688.

14. Sasaki S, Mori D, Toyo-oka K, Chen A, Garrett-Beal L, Muramatsu M, Miyagawa S, Hiraiwa N, Yoshiki A, Wynshaw-Boris A, Hirotsune S: Complete loss of Ndel1 results in neuronal migration defects and early embryonic lethality. Mol Cell Biol 2005, 25:7812-7827.

15. Pawlisz AS, Mutch C, Wynshaw-Boris A, Chenn A, Walsh CA, Feng Y: Lis1Nde1-dependent neuronal fate control determines cerebral cortical size and lamination. Hum Mol Genet 2008, 17:2441-2455.

16. Youn YH, Pramparo T, Hirotsune S, Wynshaw-Boris A: Distinct dosedependent cortical neuronal migration and neurite extension defects in Lis1 and Ndel1 mutant mice. J Neurosci 2009, 29:15520-15530.

17. Harada A, Takei Y, Kanai Y, Tanaka Y, Nonaka S, Hirokawa N: Golgi vesiculation and lysosome dispersion in cells lacking cytoplasmic dynein. J Cell Biol 1998, 141:51-59.

18. Hafezparast M, Klocke R, Ruhrberg C, Marquardt A, Ahmad-Annuar A, Bowen S, Lalli G, Witherden AS, Hummerich H, Nicholson S, Morgan PJ, Oozageer R, Priestley JV, Averill S, King VR, Ball S, Peters J, Toda T, Yamamoto A, Hiraoka Y, Augustin M, Korthaus D, Wattler S, Wabnitz P, Dickneite C, Lampel S, Boehme F, Peraus G, Popp A, Rudelius M, et al: Mutations in dynein link motor neuron degeneration to defects in retrograde transport. Science 2003, 300:808-812.

19. Chen XJ, Levedakou EN, Millen KJ, Wollmann RL, Soliven B, Popko B: Proprioceptive sensory neuropathy in mice with a mutation in the cytoplasmic Dynein heavy chain 1 gene. J Neurosci 2007, 27:14515-14524.

20. Kieran D, Hafezparast M, Bohnert S, Dick JR, Martin J, Schiavo G, Fisher EM, Greensmith L: A mutation in dynein rescues axonal transport defects and extends the life span of ALS mice. J Cell Biol 2005, 169:561-567.

21. Ilieva HS, Yamanaka K, Malkmus S, Kakinohana O, Yaksh T, Marsala M, Cleveland DW: Mutant dynein (Loa) triggers proprioceptive axon loss that extends survival only in the SOD1 ALS model with highest motor neuron death. Proc Natl Acad Sci USA 2008, 105:12599-12604.

22. Perlson $E$, Jeong GB, Ross JL, Dixit R, Wallace KE, Kalb RG, Holzbaur EL: A switch in retrograde signaling from survival to stress in rapid-onset neurodegeneration. J Neurosci 2009, 29:9903-9917.
23. Ori-McKenney KM, XU J, Gross SP, Vallee RB: A cytoplasmic dynein tail mutation impairs motor processivity. Nat Cell Biol 2010, 12:1228-1234.

24. Bagri A, Gurney T, He X, Zou YR, Littman DR, Tessier-Lavigne M, Pleasure SJ: The chemokine SDF1 regulates migration of dentate granule cells. Development 2002, 129:4249-4260.

25. Tabata H, Nakajima K: Efficient in utero gene transfer system to the developing mouse brain using electroporation: visualization of neuronal migration in the developing cortex. Neuroscience 2001, 103:865-872.

26. Bai J, Ramos RL, Ackman JB, Thomas AM, Lee RV, LoTurco JJ: RNAi reveals doublecortin is required for radial migration in rat neocortex. Nat Neurosci 2003, 6:1277-1283.

27. Nguyen L, Besson A, Heng Jl, Schuurmans C, Teboul L, Parras C, Philpott A, Roberts JM, Guillemot F: p27kip1 independently promotes neuronal differentiation and migration in the cerebral cortex. Genes Dev 2006, 20:1511-1524.

28. Nadarajah B, Brunstrom JE, Grutzendler J, Wong RO, Pearlman AL: Two modes of radial migration in early development of the cerebral cortex. Nat Neurosci 2001, 4:143-150.

29. Noctor SC, Flint AC, Weissman TA, Dammerman RS, Kriegstein AR: Neurons derived from radial glial cells establish radial units in neocortex. Nature 2001, 409:714-720.

30. Busson S, Dujardin D, Moreau A, Dompierre J, De Mey JR: Dynein and dynactin are localized to astral microtubules and at cortical sites in mitotic epithelial cells. Curr Biol 1998, 8:541-544.

31. Faulkner NE, Dujardin DL, Tai CY, Vaughan $K T$, O'Connell CB, Wang $Y$, Vallee RB: A role for the lissencephaly gene LIS1 in mitosis and cytoplasmic dynein function. Nat Cell Biol 2000, 2:784-791.

32. Howell BJ, McEwen BF, Canman JC, Hoffman DB, Farrar EM, Rieder CL, Salmon ED: Cytoplasmic dynein/dynactin drives kinetochore protein transport to the spindle poles and has a role in mitotic spindle checkpoint inactivation. J Cell Biol 2001, 155:1159-1172.

33. Varma D, Monzo P, Stehman SA, Vallee RB: Direct role of dynein motor in stable kinetochore-microtubule attachment, orientation, and alignment. J Cell Biol 2008, 182:1045-1054.

34. Basto R, Scaerou F, Mische S, Wojcik E, Lefebvre C, Gomes R, Hays T, Karess R: In vivo dynamics of the rough deal checkpoint protein during Drosophila mitosis. Curr Biol 2004, 14:56-61.

35. Ahmad FJ, He Y, Myers KA, Hasaka TP, Francis F, Black MM, Baas PW: Effects of dynactin disruption and Dynein depletion on axonal microtubules. Traffic 2006, 7:524-537.

36. Grabham PW, Bennecib M, Seale GE, Goldberg DJ, Vallee RB: Cytoplasmic dynein and LIS1 are required for growth cone remodeling and fast neurite outgrowth. J Neurosci 2007, 27:5823-5832.

37. Quintyne NJ, Gill SR, Eckley DM, Crego CL, Compton DA, Schroer TA: Dynactin is required for microtubule anchoring at centrosomes. J Cell Biol 1999, 147:321-334

38. King SJ, Brown CL, Maier KC, Quintyne NJ, Schroer TA: Analysis of the dynein-dynactin interaction in vitro and in vivo. Mol Biol Cell 2003 14:5089-5097.

39. Wang $Y$, Baraban SC: Aberrant dentate gyrus cytoarchitecture and fiber lamination in Lis1 mutant mice. Hippocampus 2008, 18:758-765.

40. Yingling J, Youn YH, Darling D, Toyo-Oka K, Pramparo T, Hirotsune S, Wynshaw-Boris A: Neuroepithelial stem cell proliferation requires LIS1 for precise spindle orientation and symmetric division. Cell 2008, 132:474-486.

41. Siller KH, Serr M, Steward R, Hays TS, Doe CQ: Live imaging of Drosophila brain neuroblasts reveals a role for Lis1/dynactin in spindle assembly and mitotic checkpoint control. Mol Biol Cell 2005, 16:5127-5140.

42. Stehman SA, Chen Y, McKenney RJ, Vallee RB: NudE and NudEL are required for mitotic progression and are involved in dynein recruitment to kinetochores. J Cell Biol 2007, 178:583-594.

43. Tsai JW, Lian WN, Kemal S, Kriegstein AR, Vallee RB: Kinesin 3 and cytoplasmic dynein mediate interkinetic nuclear migration in neural stem cells. Nat Neurosci 2010, 13:1463-1471.

44. McKenney RJ, Vershinin M, Kunwar A, Vallee RB, Gross SP: LIS1 and NudE induce a persistent dynein force-producing state. Cell 2010, 141:304-314

45. Soppina V, Rai AK, Ramaiya AJ, Barak P, Mallik R: Tug-of-war between dissimilar teams of microtubule motors regulates transport and fission of endosomes. Proc Natl Acad Sci USA 2009, 106:19381-19386.

46. Hendricks AG, Perlson E, Ross JL, Schroeder HW, Tokito M, Holzbaur EL: Motor coordination via a tug-of-war mechanism drives bidirectional vesicle transport. Curr Biol 2010, 20:697-702 
47. Pramparo T, Youn YH, Yingling J, Hirotsune S, Wynshaw-Boris A: Novel embryonic neuronal migration and proliferation defects in Dcx mutant mice are exacerbated by Lis1 reduction. J Neurosci 2010, 30:3002-3012.

48. Mikami A, Paschal BM, Mazumdar M, Vallee RB: Molecular cloning of the retrograde transport motor cytoplasmic dynein (MAP 1C). Neuron 1993 10:787-796.

doi:10.1186/1749-8104-6-26

Cite this article as: Ori-McKenney and Vallee: Neuronal migration defects

in the Loa dynein mutant mouse. Neural Development 2011 6:26.

Submit your next manuscript to BioMed Central and take full advantage of:

- Convenient online submission

- Thorough peer review

- No space constraints or color figure charges

- Immediate publication on acceptance

- Inclusion in PubMed, CAS, Scopus and Google Scholar

- Research which is freely available for redistribution

Submit your manuscript at www.biomedcentral.com/submit
() Biomed Central 